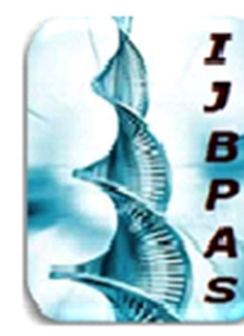

International Journal of Biology, Pharmacy and Allied Seiences (IJBPAS)

'A Bridge Betuen Caboratory and QRendo'

www.ibpas.com

\title{
TABLETS OF HG PLUS IMPROVES MALE INFERTILITY
}

\section{SMITA NARAM ${ }^{1}$, DEEPAK MAHAJAN ${ }^{2 *}$ AND HEMANG PAREKH ${ }^{3}$}

1: Department of Research and Development, Ayushakti Ayurveda Pvt Ltd, Bhadran nagar cross road, Malad, Mumbai-64

2: Research Head, Ayushakti Ayurveda Pvt Ltd, Bhadran nagar cross road, Malad, Mumbai- 64

3: Medical Head, Ayushakti Ayurveda Hospital, Bhadran nagar cross road, Malad, Mumbai-64

*Corresponding Author: E Mail: Dr. Deepak Mahajan: drdeepakm@ayushakti.com

Received $9^{\text {th }}$ May 2021; Revised $10^{\text {th }}$ July 2021; Accepted 29 ${ }^{\text {th }}$ Aug. 2021; Available online $15^{\text {th }}$ Dec. 2021

https://doi.org/10.31032/IJBPAS/2021/10.12.1024

\begin{abstract}
An estimated 5-10 percent of couples are classified as infertile, which means that they have been trying to get pregnant with frequent, unprotected intercourse for at least a year with no success. In about half the cases, male infertility is a factor. Causes of male infertility include abnormal sperm production or function and/or impaired delivery of sperm.

Male infertility is defined as inability to have a child after one or more year of unprotected sexual intercourse. Ayurveda lays emphasis on treating a disease naturally. Natural remedies for male fertility aims in enhancing the sperm quantity, quality and improves the male reproductive health. For proper functioning of male reproductive system, proper diet with required minerals and vitamins is very important.

In this article we conclude how HG plus table is beneficial for male infertility.
\end{abstract}

Keywords: Infertility, semen, sperm, Growth hormone

\section{Background :}

General health and lifestyle of a man may affect his fertility, although Modern science has made commendable advancements in identifying the causes but is still unable to put forth the treatment for the problem. Some common causes of infertility related to health and lifestyle include [1].

1) Alcohol and drugs

a) For example, Anabolic steroids, cocaine, marijuana etc.

2) Emotional stress

a) Stress may interfere with certain hormones needed to produce sperm. 
3) Life style generated disorders

a) Like Obesity, Diabetes etc. may cause hormone and other metabolic changes which reduce male fertility.

4) Electromagnetic radiation

a) Such like laptop, computers, cell phone, $\mathrm{x}$-rays etc.

5) Malnutrition

a) Deficiencies in nutrients such as vitamin c, selenium, zinc and folate may contribute to infertility.

6) Tobacco smoking

7) Environmental exposure:

i) Indoor Pollutions - Pesticides and other chemicals.

ii) Outdoor Pollutions - Pollution due to vehicles, factories etc.

Infertility Treatment With Ayurveda:

Infertility in Ayurveda has been described as Vandhyatwa - failure to achieve conception by a couple of mature age, having normal coitus, during an appropriate period of ritu-chakra (menstrual cycle), regularly for over a year.The causes of the above have been stated by Charakacarya as due to defects of the bijamsha (spermatozoa and ova). Elaborating further, he mentions regarding clarity and normalcy of "manas and hridaya' (the mental state), properly functioning vayu (nervous system), acceptance of shukra (semen) by the yoni (vagina), in other words, deposition of semen high in the vagina, proper aahara (food and digestion), vihaara (good conduct and lifestyle of the couple), vichaara (thought process, mental stability) and bala (strength and health) are factors essential for procreating.

Causes of male infertility according to Ayurveda

- Shukradosha (Defects in semen- volume, morphology, motility, sperm count, obstruction in the genital tract or erectile dysfunction)

- Ativyayama (overexertion leads to vitiation of the vatadosha, which is the number one cause of infertility)

- Aaharadosha (improper food habits, not consuming a balanced diet, in turn leading to defective digestion, vitiation of the tridoshas-vata, pitta and kapha, which causes malnutrition)

- Viharadosha (abnormalities in lifestyle- over exercise or not exercising at all, late nights, alcohol overconsumption etc.)

- Loss of bala or strengthdebilitating diseases, trauma 
to genital organs, muscle weakness, infections or stricture causing obstructive pathology, which could cause infertility.

- Manasadoshas - refers to mental stress, inability to concentrate which could lead to premature ejaculation or erectile dysfunction.

\section{Name of Herbal Combination} HG PLUS TABLET

\section{Manufacturer :}

Ayushakti Ayurveda Pvt Ltd pharmacy, Plot number 78, Stice, Musalgaon, Sinnar, Nashik- 422112

\section{Herbal formulation}

\begin{tabular}{|c|c|c|c|}
\hline$\dot{E}$ & SANSKRIT NAME & LATIN NAME & QTY. IN mg. \\
\hline 1 & KapikachuBeej (Atmagupta) Ghan & Mucunaprurita & $\mathbf{5 0 0}$ \\
\hline 2 & GokshuraGhan & Tribulusterrestris & 150 \\
\hline 3 & AshvagandhaGhan & Withaniasomnifera & 124 \\
\hline 4 & Trikatu & $\begin{array}{l}\text { Zingiberofficinale rhizome, Piper } \\
\text { longum fruit, Piper nigrum fruit }\end{array}$ & $\mathbf{6}$ \\
\hline & Total & & $\mathbf{6 4 5} \mathbf{~ m g}$ \\
\hline
\end{tabular}

\section{Kapikachu Beej (Atmagupta) Ghan}

M. pruriens, which belongs to the family Fabaceae, is a tropical legume and native to India, the Caribbean and Africa. The plant is indigenous to and commonly found in South Western Nigeria. The plant has been screened for its phytochemical constituents and reported to be rich in alkaloids, tannins anthraquinones, saponins, flavonoids and cardiac glycosides [2] making the various parts of the plant, including leaves, roots and seeds, to possess some medicinal properties [3].

The seed of the plant has been reported to improve reproductive performances in male animal and humans due to its active compound L-3,4dihydroxyphenylalanine (L-DOPA) [4].

In addition, antioxidant, anti-inflammatory, neuroprotective, antidiabetic, antiepileptic, antibacterial and cardioprotective properties of the plant have been found [5]. Also, studies have shown that L-DOPA stimulates the secretion of gonadotropin releasing hormone $(\mathrm{GnRH})$, which in turn, stimulates the secretion of FSH and LH from the anterior portion of pituitary gland [6].

An imbalance between productions of free radicals or reactive oxygen species (ROS) is known to result into oxidative stress which lead to damage to lipids (lipid peroxidation), proteins, carbohydrates and 
nucleic acids and this has been identified as a major factor contributing to poor sexual performances among male humans [7].

The vital role of antioxidant defence, which focused on the protection of cells by scavenging the free radicals produced through oxidation in the body, has been reported,

After taking M.Pruiens it increases in the activities of antioxidant enzymes (CAT, SOD GPx) and GSH which improves male performance. $M$. pruriens significantly ameliorated psychological stress and seminal plasma lipid peroxide levels along with improved sperm count and motility. Treatment also restored the levels of SOD, catalase, GSH, and ascorbic acid in seminal plasma of infertile men. It reactivates the antioxidant defence system of infertile men and also helps in the management of stress and improves semen quality [8].

\section{Gokshura Ghan:}

Gokshura obtained from the dried fruits of the Gokshura tree which goes by the botanical name Tribulusterrestris, is a perennial plant that thrives in both cool and hot temperatures and is native to Africa, Australia, Southern Asia, and Southern Europe.

The plant Tribulus terrestris Linn. (Zygophyllaceae) popularly known as puncture vine is a perennial creeping herb with a worldwide distribution. Since ancient times it is regarded as an aphrodisiac in addition to its beneficial claims on various ailments such as urinary infections, inflammations, leucorrhoea, oedema, and ascites [9]. T. terrestris has long been used in the traditional Chinese and Indian systems of medicine for the treatment of various ailments and is popularly claimed to improve sexual functions. Administration of $T$. terrestris improves plasma testosterone which directly linked to spermatogenesis. Tribulus terrestris can enhance libido and has beneficial effects on semen parameters such as count, motility, and morphology [10].

\section{Ashvagandha Ghan:}

Withania somnifera (Ashawagandha) is very revered herb of the Indian Ayurvedic system of medicine as a Rasayana (tonic). Ashwagandha is an effective herbal remedy for stress and infertility. It improves blood circulation throughout the body and enhances sperm quality naturally. Apart from curing sperm problems, intake of Ashwagandha helps in improving the overall health and wellbeing of a person. Ashwagandha flowers have potent diuretic and aphrodisiac properties which is used for improving fertility. The root extract induced a marked impairment in libido, sexual performance, sexual vigour, and penile erectile dysfunction [11]. 
Aqueous extract improved

spermatogenesis, which may be due to increased interstitial cell stimulating hormone and testosterone-like effects as well as the induction of nitric oxide synthase [12]. Ashwagandha root extract administered to the oligospermic patients resulted in a significantly greater improvement in spermatogenic activity and serum hormone levels as it helps in balancing hormone level [13].

\section{Trikatu:}

TrikatuChurnais a popular Ayurvedic formulation used in Ayurvedic Medicine.

As name suggests, Trikatu is a combination of Three spices or herbs that ae hot ( katu). It is a blend of equal parts of pippali or long pepper (Pier Longum L), Black pepper Piper nigrum L) and dry ginger or sunthi (rhizomes of zingiberofficinalis). There is a shukradhatu inside the human body which blocks the flow of sperm within the testes. Guduchi, Gokshura and Triphalachurna are the proven remedies. It removes such blockages and boosting fertility process as well.

\section{Zingiber officinale:}

The ginger rhizome (Zingiber officinale L., Family Zingiberaceae) that commonly used as a spice contains several biologically active compounds such as gingerol, shogaols, gingerdiol and gingerdione. It is also medically used for its immunomodulatory, anti-tumorigenic, antiinflammatory, antiapoptotic and antioxidant properties. In addition, it was found that Zingiberofficinale is associated with a beneficial effect on male reproductive functions in rats, which confirmed by other studies on the increased sperm counts, motility, testosterone, and decreased malonhydialdehyde levels.

It was also observed that the administration of ginger can significantly increase the testosterone level in plasma and stimulate spermatogenesis. Although the effectiveness of ginger as an antioxidant agent has been exploited in animals, little human research has been conducted on its activity on male reproductive functions

\section{[14-17].}

Piper nigrum :

Black pepper plays an important role in improving fertility in males. Black pepper increases the level of testosterone (male sex hormone). Black pepper is rich in magnesium and zinc. Such a composition increases the level of male sex hormones. Black pepper contains zinc, a potent antioxidant that reduces oxidative stress and improves fertility.

\section{RESULT:}

We Conclude That HG PLUS TABLET Possess Male Infertility Effect which occur due to Hormonal Imbalance, Deficit Of Testosterone And Human Growth 
Hormone, Male Infertility, High FSH In

Male, Azoospermia, Oligospermia,

Weakness, Under Active Spermatogenesis,

Premature Ejaculation, Erectile

Dysfunction.

\section{DISCUSSION:}

By addressing simple lifestyle factors and providing HG PLUS as remedies can help male clients optimize their fertility. Thus it can be concluded that there are a large number of factors that lead to impotency of males, but with the right precautions and Ayurvedic cures, this medical condition can be treated, positively. All you need is a balanced diet, proper lifestyle habits, and correct medical assistance. Correction the life style helps in controlling other metabolic disorders like Diabetes mellitus, obesity etc. and hence related impotency too.

Thus HG Plus tablet improving sexual desire as well as sexual performance and erectile dysfunction, vasodilatation, increased testosterone level, brain monoamines, effect on pituitary-gonadal axis.

\section{REFERENCES}

[1] AyurvedLine, DrNayak, Brahmanand. Seethram publication, 11thed, Bangalore; 2010. Part I. p. $87,88,176,178$

[2] Vadivel and Janardhanan, 2000; Nebedum et al., 2010; Agbafor and Nwachukwu, 2011; Nwaoguikpe et al., 2011
[3] Agbafor and Nwachukwu, 2011; Nwaoguikpe et al., 2011

[4] Ahmad et al., 2008; Shukla et al., 2009; Mutwedu et al., 2019

[5] Misra and Wagner, 2004; Majekodunmi et al., 2011; Uma and Gurumoorthi, 2013; Obogwu et al., 2014

[6] Vermes et al., 1979; Singh et al., 2013

[7] Agarwal and Said, 2005; Agarwal et al., 2008

[8] K. K. Shukla, A. A. Mahdi, M. K. Ahmad, S. P. Jaiswar, S. N. Shankwar, and S. C. Tiwari, "Mucunapruriens reduces stress and improves the quality of semen in infertile men," Evidence-Based Complementary and Alternative Medicine, vol. 7, no. 1, pp. 137144, 2010.

[9] P. Georgiev, M. Dimitrov, and S. Vitanov, "Effect of Tribestan (from Tribulusterrestris) on plasma testosterone and spermatogenesis in male lambs and rams," VeterinarnaSbirka, vol. 86, no. 3, pp. 20-22, 1988.

[10] https://fertilitypedia.org/blog/tribul us-terrestris-role-male-fertility/

[11] I. Ilayperuma, W. D. Ratnasooriya, and T. R. Weerasooriya, "Effect 
of Withaniasomnifera root extract on the sexual behaviour of male rats," Asian Journal of Andrology, vol. 4, no. 4, pp. 295-298, 2002.

[12] T. Iuvone, G. Esposito, F. Capasso, and A. A. Izzo, "Induction of nitric oxide synthase expression

by Withaniasomnifera in macrophages," Life Sciences, vol. 72, no. 14, pp. 1617-1625, 2003.

[13] V. R. Ambiye, D. Langade, S. Dongre, P. Aptikar, M. Kulkarni, and A. Dongre, "Clinical evaluation of the spermatogenic activity of the root extract of Ashwagandha

(Withaniasomnifera) in oligospermic males: a pilot study," Evidence-Based Complementary and Alternative Medicine, vol. 2013, Article ID 571420, 6 pages, 2013.

[14] Ikpeme EV, Udensi OU, Ekerette EE, Okon UH. Potential of Ginger (Zingiberofficinale) Rhizome and Watermelon (Citrulluslanatus) Seeds in Mitigating AspartameInduced Oxidative Stress in Rat Model. Res $\quad J \quad M e d$ Plant. 2016;10:55-66. [Google $\underline{\text { Scholar] [Ref list] }}$

[15] Mohammadi F, Nikzad H,
Taghizadeh $M$, Taherian A, Azami-Tameh A, Hosseini SM, MoravvejiAAndrologia. 2014 Aug; 46(6):680-6.

[16] Morakinyo AO, Achema PU, Adegoke OA. Effect of Zingiberofficinale (Ginger) on sodium arsenite-induced reproductive toxicity in male rats. Afr $\quad J \quad$ Biomed Res. 2013;13:39-45. [Google Scholar] [Ref list]

[17] Mares AK, Abid W, Najam WS. The effect of Ginger on semen parameters and serum FSH, LH \& testosterone of infertile men. Tikrit Med J. 2012;18:322. [Google $\underline{\text { Scholar] [Ref list] }}$ 